\title{
Geoinformation monitoring of the territory of Western Siberia
}

\author{
Natalia Martynova ${ }^{1, *}$ and Valentina Budarova ${ }^{1}$ \\ ${ }^{1}$ Tyumen Industrial University, 38, Volodarskogo St., 625000, Tyumen, Russia
}

\begin{abstract}
The article is devoted to the use of GIS technology for the control of swamp areas and environmental problems associated with the drainage of swamps in the industrial development of the West Siberian region, the main functions of swampy areas in the biosphere. The study examines the problems of drainage of swampy lands on the example of the territory of Western Siberia. Problems of the "greenhouse effect" and global climate warming, as well as problems of degradation and conservation of permafrost in the cryolithozone. It is established that swamps, as a natural mechanism for removing carbon dioxide from the atmosphere, are the only land geosystems with a constant flow of atmospheric carbon there. The problem associated with gas hydrates and the possibility of activation of microorganisms during the degradation of permafrost has been identified. To date, in the course of scientific experiments and studies based on the observation method, it has been established that natural gas hydrates are extremely sensitive to various technogenic factors.
\end{abstract}

\section{Introduction and problem statement}

In the modern world, there is an increasing need to obtain information to study and predict the needs of the country, so the role of spatial data, remote sensing data, as well as services, services and products created on their basis is increasingly increasing. Spatial data is used to solve problems facing government agencies at all levels (federal, regional, municipal).

To effectively use the potential of spatial data, to meet the needs of the economy in geoinformation products and services, it is necessary to develop an information infrastructure and a digital spatial data platform on a national scale. This will lead to a significant acceleration of the development of the country's territories, a more in-depth information support of the economy through the integration of geoinformation systems at various levels of government (departmental, municipal and others), providing stakeholders with quick access to high-quality and up-to-date spatial data. The efficiency of obtaining information will increase.

Modern geographic information systems help not only in collecting spatial data of urban areas and agricultural land, but are also used for environmental monitoring, cadastral activities and in various sectors of the economy in the country.

\footnotetext{
* Corresponding author: natali.cherdanceva@mail.ru
} 
It is no secret that the current environmental situation in Russia is unfavourable. The result of the industrial development of Russia is large emissions of mining and chemical industries, which enter the environment in huge quantities, lead to changes in the composition in the atmosphere, soil, and water. These changes negatively affect the state of the environment; they can affect the state of the climate, flora and fauna, areas of rivers, lakes, reservoirs, and many other processes that occur in nature. The high anthropogenic load of the territories, combined with the unfavourable socio-economic situation in Russia, also creates a real threat of massive, irreversible changes in natural processes.

Therefore, the use and expansion of geographic information systems (GIS) tools for obtaining information about the state of the environment is becoming the most significant task today, since the use of GIS technologies will help to obtain operational, high-quality, up-to-date information about the environmental situation in a particular territory, which will allow you to quickly and competently take measures to eliminate emerging environmental problems or disasters.

One example of the application of geoinformation technologies for monitoring the ecological state of the environment is the tracking of the swamp areas of the West Siberian Plain.

The West Siberian plain is the largest on the globe, a characteristic feature of which is its strong swampiest. Bogs occupy three physical and geographical zones (forest-steppe, taiga, tundra), where $39 \%$ of the world's peat reserves are concentrated. The West Siberian region is characterized by huge reserves of peat, so its territory is watered, impassable, and in some places completely inaccessible. In economic terms, it is the largest peat region in the world with $39 \%$ of the world's peat reserves.

The West Siberian plain includes forest-steppe, forest and tundra natural-geographical zones. The composition of the municipal division includes: Altai, Kemerovo, Novosibirsk, Tyumen, Omsk and Tomsk regions.

In the West Siberian Economic Region, as of 01.01.88, 5004 peat deposits with a total area of 32474.2 thousand hectares in the industrial border and 113712.8 million tons of peat resources were taken into account. Of these, more than $50 \%$ is located in the Tyumen region and about $30 \%$ - in the Tomsk region. The peat resources of the Kemerovo Region and the Altai Territory are relatively small, amounting to 178.8 million and 203.4 million tons, respectively. The study of peat resources in the West Siberian Economic Region as a whole, as well as in most of its constituent regions, is low, and more than $90 \%$ of peat resources are forecasted.

Peat reserves, as well as mineral reserves, are divided according to the degree of study into explored (categories A, B and C1), pre-estimated (category C2 and forecast (categories $\mathrm{P} 1, \mathrm{Rg}, \mathrm{P} 3$ ). At the same time, the study of peat resources in the southern regions is quite significant.

More than $96 \%$ of the proven peat reserves of the district are located in 148 large peat deposits with an area of more than 1000 hectares. At the same time, peat deposits with an area of 50 to 1000 hectares predominate in terms of quantity, although peat reserves in them account for about $3 \%$ of the explored ones. Less than $1 \%$ of peat reserves are concentrated in 343 explored peat deposits with an area of up to 50 hectares.

The main peat reserves (more than $70 \%$ ) are concentrated in 106 large peat deposits with an area of more than 50 thousand hectares. Among them, a group of unique peat deposits is distinguished, such as Vasyuganskoe (53 thousand km2), Kantsiyarskoe (132 km2), Laimenskoe (502 km2), Salymo-Yuganskoe (732 km2) [1].

Western Siberia is one of the main industrial centres of the Russian Federation. The main industry of the West Siberian region, of course, is the fuel industry, since the largest oil and gas fields in Russia are concentrated here. As of 2019 , it produces about $70 \%$ of oil and $90 \%$ of gas from the total volume of Russian production, but there are also other 
industries such as ferrous and non-ferrous metallurgy, mechanical engineering, chemical, forestry and food industries.

The active industrial development of the West Siberian region has recently been characterized by a serious deterioration of the environmental situation. Many cities and industrial areas of Western Siberia can be classified as an ecological disaster zone. The main reason for this is the discrepancy between the scale of man-made impact on the natural environment and measures for its conservation, restoration and protection. Specifically, this is reflected in the continuous increase in the area and volume of oil and gas production, the use of old technologies and the deterioration of existing ones, the presence of dangerous chemical and nuclear facilities. Complicating factors include poor consideration of the resistance of natural landscapes to man-made impacts, which is associated with the peculiarities of the zone of distribution of multi-permafrost rocks and the climatic conditions of the dispersion of pollutants in the atmosphere.

The deterioration of the environmental situation is manifested not only in the contamination of the air basin, soil and water resources with radioactive waste, heavy metals, and petrochemical products, but also in another problem that is no less important the drainage of the West Siberian swamps for industrial needs.

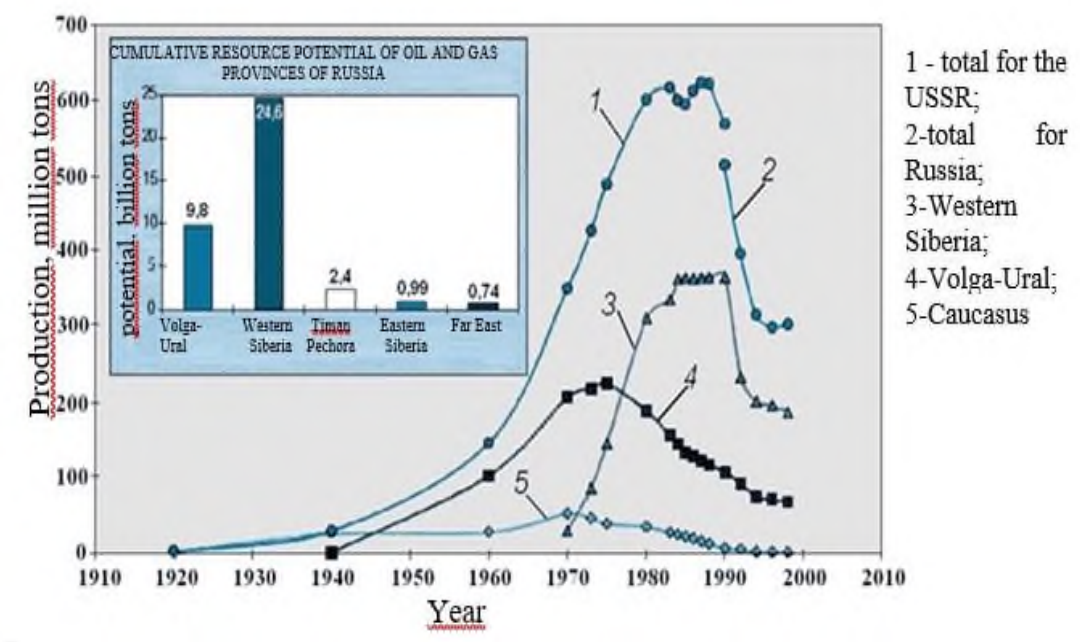

Fig. 1. Dynamics of carbon mining by regions of the Russian Federation (Konoplyanik A. A., 2000).

West Siberian swamps are unique ecological systems and occupy up to $50-70 \%$ of the entire area of Western Siberia, the primary centres of water logging were depressions in the relief, mainly occupied by lake pits with initial deposits of sapropels and peat sapropels about 8-8. 5 thousand years old. In the south of the West Siberian Plain, the age of peat lands is half that. The maximum area of wetlands in the Vasyugan land, Konda and Surgut woodlands associated with outwash fields melting and retreating glaciers. Polesie, for example, is frozen in $50-60 \%$ of the territories, and together with wetlands occupy the vast majority of the area [2-3].

The West Siberian swamps did not always determine the shape of the earth's surface in northern and temperate latitudes, being the result of the post-glacial period of Holocene history. This is evidenced by the fact that the geographical distribution of swamps-swamps and wetlands: with organo-mineral (forest) and mineral waterlogged soils corresponds to the outlines of regions that have undergone Quaternary glaciations [4].

Swamp ecosystems, being an indispensable attribute of the landscape shell in Western Siberia, perform a number of functions: hydrological, geomorphological, climatological, 
etc., are the last natural complexes where medicinal and food wild plants have been preserved, as well as a habitat for rare species of the animal world. Marsh plants have a high nutritional and medicinal value, which is also actively used [5].

However, they also contain the most valuable mineral deposits. The discovery of the richest deposits of oil and gas in the swampy areas of Western Siberia led to the rapid development of swamp fields for production. This state of affairs is proved by the dynamics of carbon mining in the regions of the Russian Federation (Fig. 1) [6].

At the expense of the drained territories, active peat development is underway, the area of arable land is increasing, since the drained lands are rich in fertilizer, they give high yields. All this threatens their complete destruction.

The purpose of the study is to determine the impact of industrial development on the state of swamps in Western Siberia by territorial coverage using GIS technologies.

The aim of the study is to develop a digital model of wetlands and water resources in the territory of Western Siberia; to assess the dynamics of the development of the territory, taking into account the influence of industry.

Tracking the dynamics of changes in the water resources of Western Siberia can be tracked using comparative analysis methods and modern remote sensing technologies (based on images), and GIS technologies (using software tools).

Therefore, from the point of view of the territorial coverage of Western Siberia as one of the world's major sources of peat (39\% of the world's reserves), research should provide for a global approach, taking into account the relationship of all natural factors and climatic conditions. The study should be based on the indicators of the water balance of the territory, since one of the characteristics of the existence of swamps is water exchange.

\section{Methods of research and the materials used}

Balanced development of the territory is possible with the use of modern, reliable and standardized information about spatial objects. By creating digital models and geospatial data, it is possible to achieve maximum efficiency in the development of territories through rational planning of residential, industrial and recreational zones, rational zoning of forest and agricultural land, design of safe roads, etc.

To date, a number of important technologies can be identified that determine the vector of development of the geoinformation environment at various stages of collecting, processing and applying spatial information (Fig. 2).

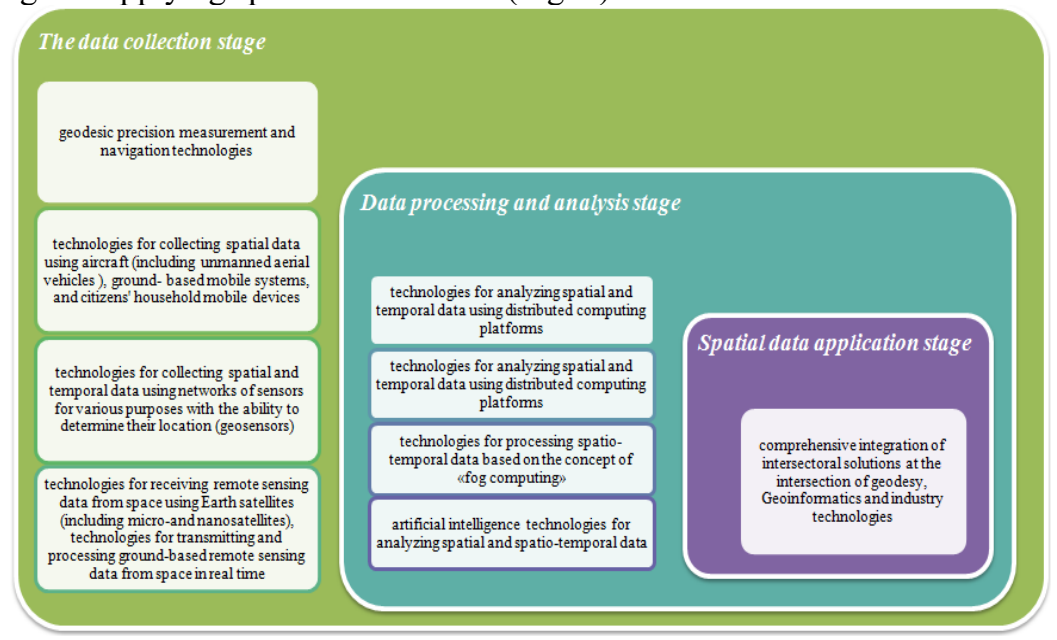

Fig. 2. Stages of collecting, processing and applying spatial information (authors). 
In this regard, it is important to ensure the possibility of using modern technologies in the system of regular geoinformation monitoring, which would allow forming a comprehensive vision, analyzing changes, providing management and regulation of the analyzed space, as well as coordinating the development of software tools as necessary. Also in this regard, the digitalization of the field of spatial data collection, processing and analysis creates a high investment potential through the development of existing and the creation of new markets for data, services and services. Therefore, the creation of digital models of territories allows you to create a system of rational use of land, water resources and space objects.

Geoinformation technologies allow ensuring the functioning of the T-shaped system of operational monitoring. This approach is well illustrated in the scientific work of G. I. Glagolev [7]: "The use of geoinformation systems allows us to model the development of the ecological situation in various natural environments and clearly see the dependence of the state of land on sources of pollution, to obtain a comprehensive assessment of the state of environmental objects based on heterogeneous data."This effect has been extensively studied [8-14]. The method of observation in the geoinformation space of the territory of swamps and water resources using GIS technologies is shown in Figure 3.

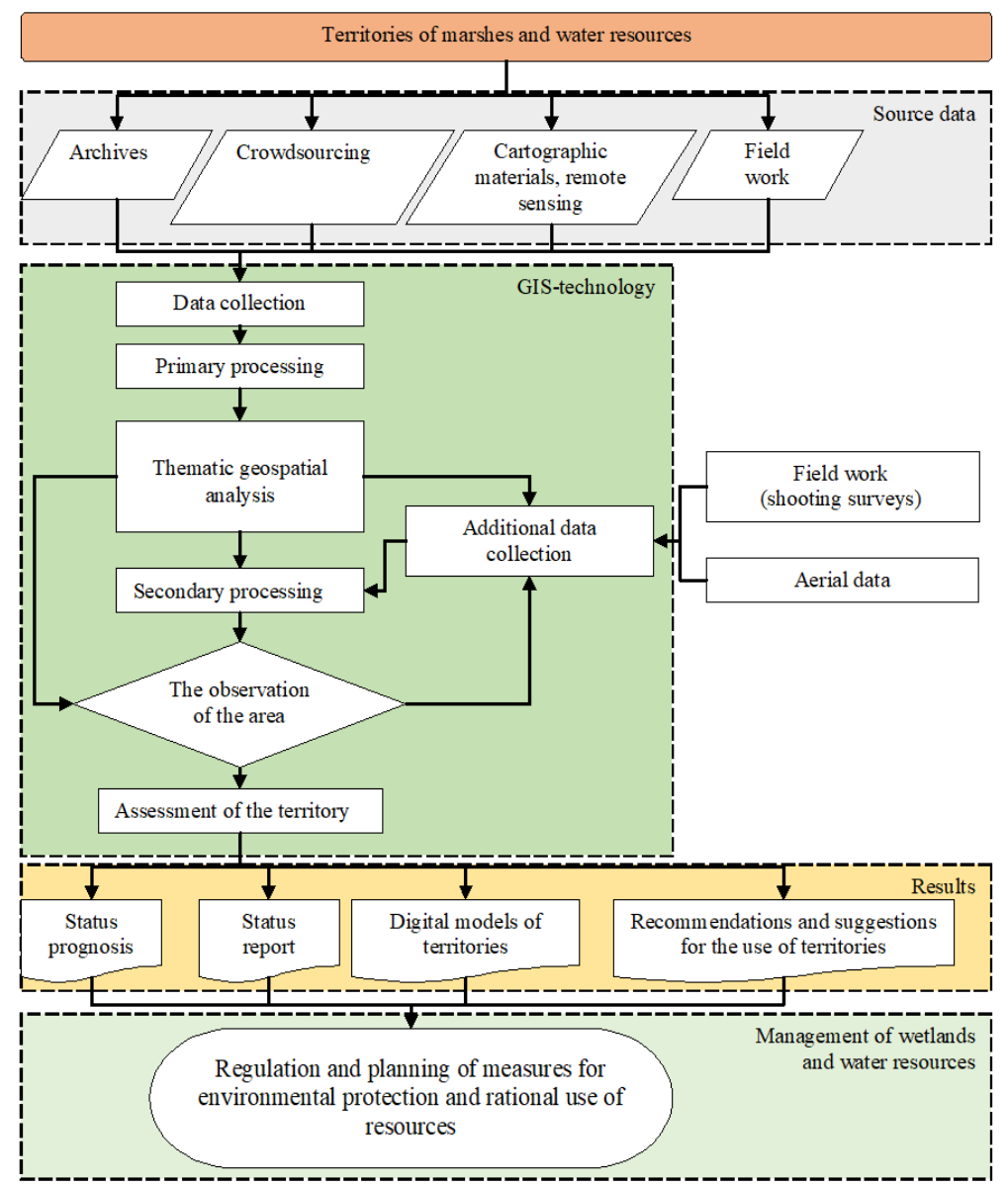

Fig. 3. Methodology for monitoring the geoinformation space of the territory of swamps and water resources using GIS technologies (authors). 
This method allows us to give the most advanced assessment of regulation, planning, forecasting of environmental protection and rational use of resources using the maximum possible multi-time data sources and technologies for processing and presenting information using GIS $[14,15]$.

The research area is the territory of Western Siberia.

The objects of the study are swamps and water resources of the territory of Western Siberia.

The analysis of the dynamics of changes in the territory of swamps is based on images from open sources, modeling data.

The initial information for the analysis is provided by Google Earth open data sources in the form of images of the state of the territory of Western Siberia in 2015-2017, for which the territories of swamps and water resources are selected and determined is shown in Figure 4.

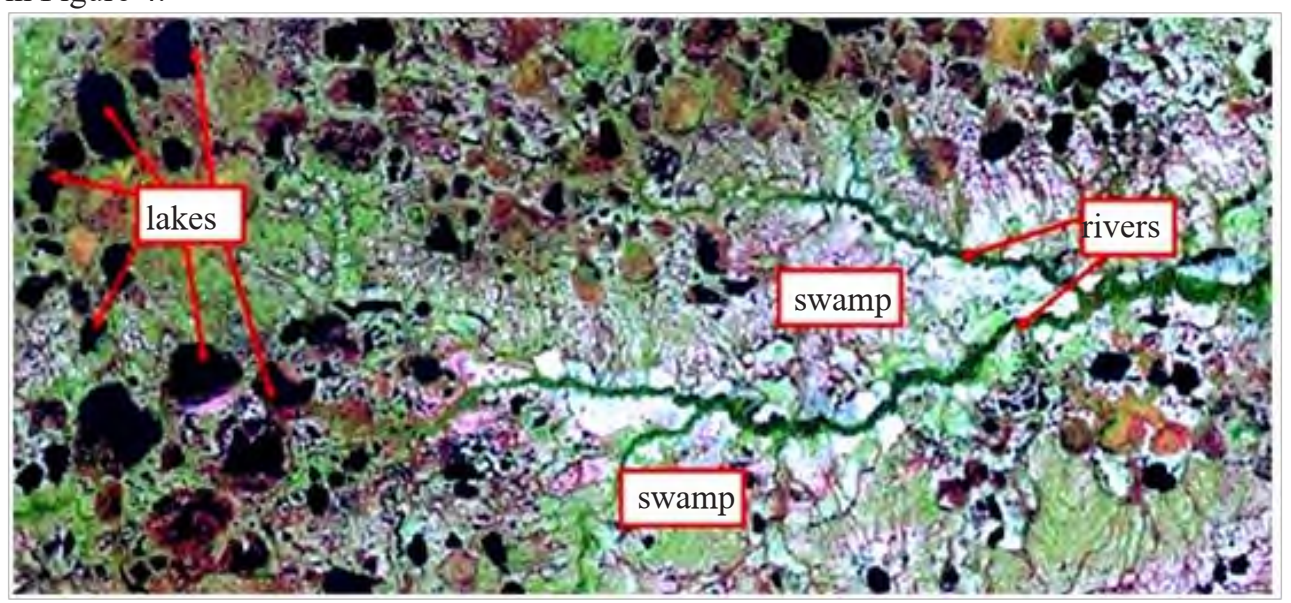

Fig. 4. Satellite image of part of the territories of Western Siberia from the Google Earth program with the indication of water bodies.

\section{Research results and discussion}

In the course research, using GIS technologies (MapInfo Professional - software) and methods of GIS analysis and image interpretation in 2015-2017, a diagram of the distribution of water resources in the territory of Western Siberia was compiled from the Google Earth program (Figure 5). In addition, a digital model of swamps and water resources was obtained, a fragment of which is shown in Figure 6.

According to the attribute database obtained during the creation of a digital terrain model in the MapInfo Professional, a decrease in the area of wetlands can be observed for the total area of wetlands from 2015-2017 (Figure 7).

The total area of swamps for 2015 was 28968 thousand hectares, for 201725401 thousand hectares. The comparison showed that the area of wetlands in 2017 less than in 20153567 ha.

It is worth noting that examined only part of the territory of Western Siberia, which are the most exposed to anthropogenic impact, the districts of the Khanty-Mansi Autonomous Region - Yugra, Yamalo-Nenets Autonomous Region, Kemerovo Region, Tyumen Region, Omsk Region. 


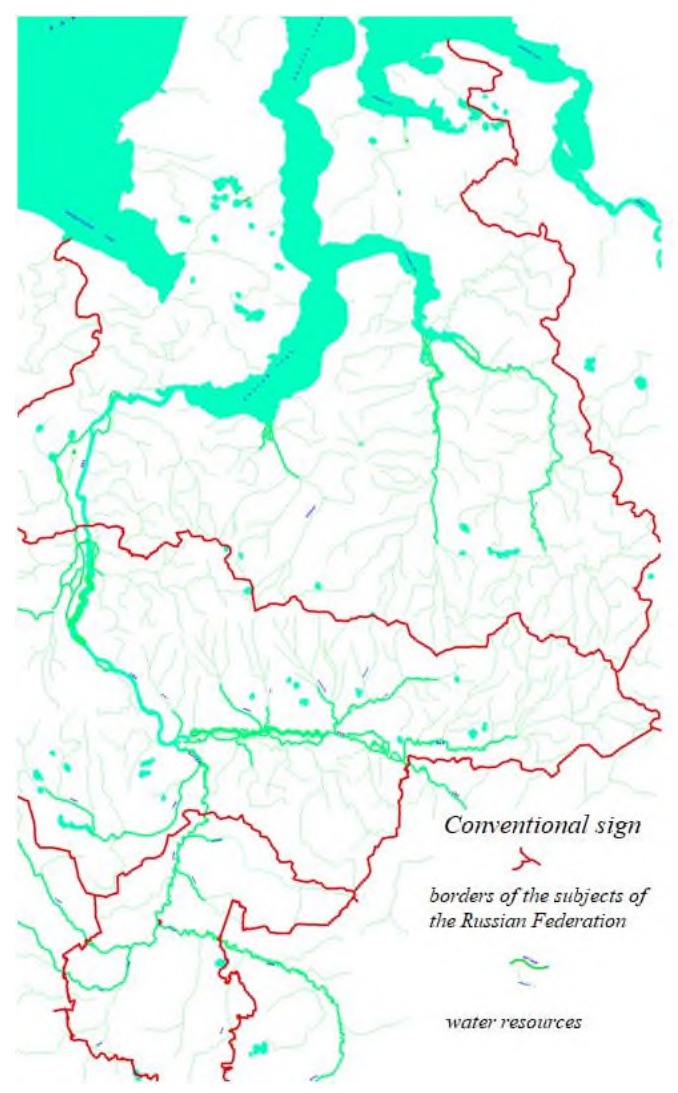

Fig. 5. Satellite image of part of the territories of Western Siberia from the Google Earth program with the indication of water bodies.

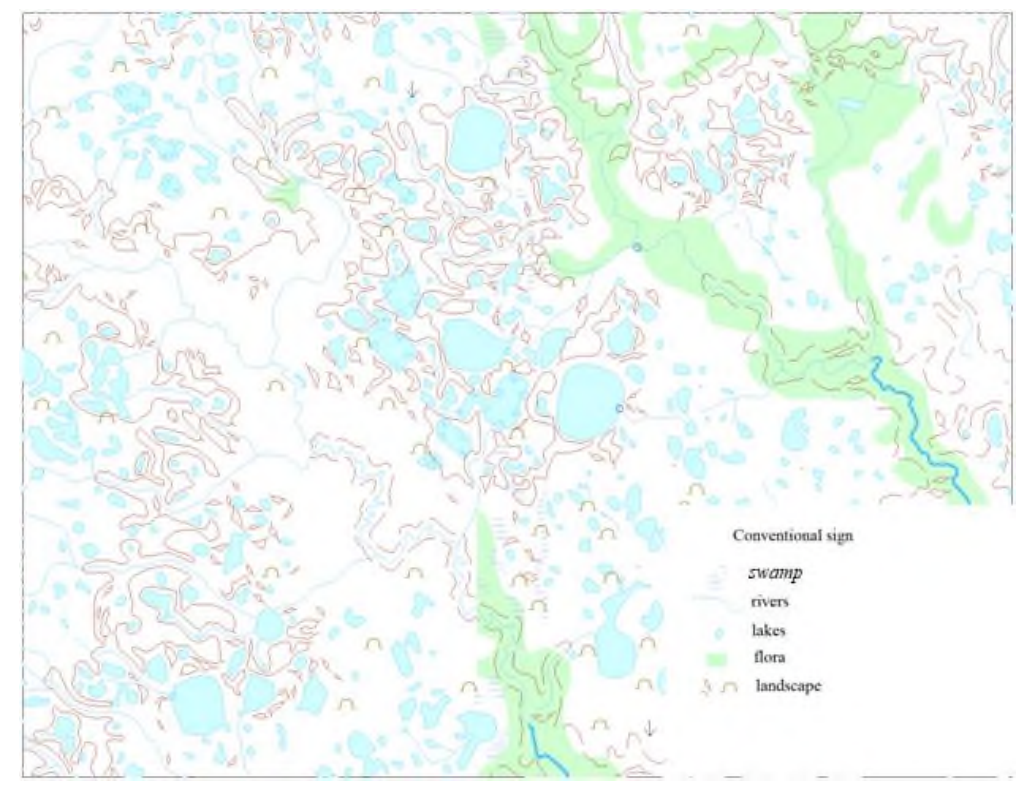

Fig. 6. Fragment of a digital model of swamps and water resources of Western Siberia Fragment. 


\begin{tabular}{|c|c|c|c|}
\hline Number & Name & Code & Area \\
\hline 463 & \multirow{2}{*}{$\begin{array}{l}\text { passable swang } \\
\text { passable swamp }\end{array}$} & 7.23.1.1.1. & 240031.24 \\
\hline 412 & & 7.2.3.1.1.1. & 1217812.99 \\
\hline $37 \mathrm{~B}$ & \multirow{2}{*}{$\begin{array}{l}\text { passable swang } \\
\text { passable swamig }\end{array}$} & 7.23.1.1.1. & 194450,79 \\
\hline 399 & & 7.23.1.1.1. & 292083,43 \\
\hline 391 & \multirow{2}{*}{$\begin{array}{l}\text { passable swang } \\
\text { passable swang }\end{array}$} & 7231.1 .1$. & 296851,6 \\
\hline 397 & & 7.23.1.1.1. & 204862.61 \\
\hline 407 & \multirow{2}{*}{$\begin{array}{l}\text { passable swang } \\
\text { passable swamp }\end{array}$} & 7.2.3.1.1.1. & 270444.77 \\
\hline 433 & & 7.23.1.1.1. & 330445,58 \\
\hline 437 & passable swamp & 7.23 .1 .1 .1$. & 227246,23 \\
\hline
\end{tabular}

2017

\begin{tabular}{|c|c|c|c|}
\hline Number & Name & Code & Area \\
\hline 1537 & parsable suang & $2,1,1,2$ & 127428,99 \\
\hline 1538 & parrable swamp & 2.1 .1 .2 & 24800,25 \\
\hline 1519 & passable swamp & $2.1,1,2$ & $392,445,16$ \\
\hline 1540 & parsable swamp & 2.1 .1 .2 & 364206.87 \\
\hline 1541 & parsable swamp & 2.1 .2 & $138,412,99$ \\
\hline 1542 & passable swamp & 21.1 .2 & 55000,82 \\
\hline 1543 & passable sivamp & $2,1,1,2$ & 29593,3 \\
\hline 1544 & parsable swamp & $2.1,1.2$ & 75599,01 \\
\hline 1545 & passable swamp & 2.1 .1 .2 & 41018,86 \\
\hline
\end{tabular}

Fig. 7. Attribute databases of swamp areas for 2015-2017.

The process of reducing the area of wetlands can also be observed in reports on the environmental situation in Western Siberia. The distribution of land under swamps in all categories of land in the Omsk Region, Khanty-Mansi Autonomous Region -Yugra, and Kemerovo Region is presented in Table 1.

Table 1. Font styles for a reference.

\begin{tabular}{|c|c|c|c|}
\hline \multirow{2}{*}{ Regions and autonomous districts } & \multicolumn{3}{|c|}{ Swamp area. (thousand ha.) } \\
\cline { 2 - 4 } & $\mathbf{2 0 1 6}$ & $\mathbf{2 0 1 7}$ & $\mathbf{2 0 1 8}$ \\
\hline Omsk region & 2142,8 & 2071,6 & 2026,8 \\
\hline $\begin{array}{c}\text { Khanty-Mansi Autonomous region - } \\
\text { Yugra }\end{array}$ & 19914,5 & 19914,5 & 19913,4 \\
\hline Kemerovo region & 90,7 & 90,5 & 90,4 \\
\hline
\end{tabular}

The table shows that the swamp areas of the regions of Western Siberia are decreasing annually. However, it is worth bearing in mind that not only anthropogenic factors, but also natural factors, affect the reduction of the swamp area.

The results of the study showed that the drainage of wetlands of Western Siberia activates a number of processes that form the problem of the greenhouse effect and global warming, as well as the degradation and preservation of permafrost, as the marshes are a natural mechanism for carbon dioxide out of the atmosphere, this is the only geosystems land with a constant flow back of the atmospheric carbon that they store two times more carbon than all the forest areas of the planet.

In connection with the active use of water resources, the issues of pollution and especially water depletion have already become of paramount importance. And here the role of the West Siberian marshes is very significant. They accumulate $1000 \mathrm{~km} 3$ of moisture, which is $2.5 \%$ of the annual flow of the Ob River in the Salekhard city area [16]. As giant vaporizers, they deliver significant amounts of water vapour - the main greenhouse gas that contributes to cloud cover-to the atmosphere. At the same time, in such a process, first, a cooling effect for rocks is manifested, since $90 \%$ of the solar energy coming to the Earth is spent on evaporation. This is important from the point of view of preserving the permafrost, its conservation, and secondly, peats have low thermal conductivity [1].

The moisture evaporating from the swamps condenses in the atmosphere around the condensation nuclei, and in the summer, the air flows of the meridian direction are transferred to the south in the amount of about $300 \mathrm{~km} 3$. in the form of liquid meridional precipitation in the territories of Kazakhstan and Central Asia. For comparison, the project of the channel for transferring water from the Irtysh River to Central Asia provided for only 
$25 \mathrm{~km} 3$. per year. It can be assumed that if there were no atmospheric drainage of the swamps of Western Siberia, many territories of Kazakhstan and Central Asia would suffer from desertification.

Also, during dehumidification, there is a serious problem associated with gas hydrates and the possibility of activation of microorganisms during the degradation of permafrost. The experimental and field data accumulated to date have shown that natural gas hydrates are extremely sensitive to various man-made influences (temperature increase, reservoir pressure decrease), as a result of which their decomposition occurs, accompanied by active gas release, changes in thermal and filtration properties.

For the formation of gas hydrates and obstacles to their expansion must be performed a certain temperature and pressure conditions. Favourable conditions for the formation of natural gas hydrates exist both on land, mainly in the areas of permafrost distribution, and almost the entire area of the sea and ocean floor, due to the favourable combination of temperatures and pressures for their formation. In the bottom sediments of the seas and oceans, gas hydrates (in particular methane hydrates) are in a solid, relatively stable state as a result of enormous pressure [17]. On land, the stable state of gas hydrates is provided by low-temperature permafrost.

During the degradation of permafrost, gas hydrates begin to break down with the release of methane into the atmosphere, increasing the greenhouse effect, and are a time bomb. Therefore, its conservation, including peat bogs as natural heat stabilizers, is very important. Therefore, it is impossible to allow the destruction of swamps in the industrial development of the northern regions. On agricultural land, the development of low-lying swamps is possible with their transformation into the original state of freshwater lakes, using the construction of agricultural landscapes based on nature-compatible technologies [18].

To all this, we can add that the degradation of permafrost negatively affects the resistance to destruction of buildings and structures, pipeline systems, roads, bridges, oil and gas storage facilities, in northern latitudes. Therefore, it is necessary to widely use different designs of heat stabilizers in large quantities.

\section{Conclusion}

The use of GIS technology will allow you to visualize the accumulated material, quickly search and select objects that fall into the area of interest. The results of water and air samples can be converted into electronic form for further processing and analysis, which will allow you to quickly identify existing environmental problems and make competent decisions to eliminate them.

The West Siberian marshes are an important part of the planet's ecosystem. The processes of drainage of swamps as a result of the industrial development of Western Siberia can cause serious irreversible environmental processes such as: violation of the temperature regime, desertification of some parts of the planet's territory, reduction of water resources, destruction of flora and fauna, etc. Therefore, the problem of dehumidification is more relevant than ever and therefore special attention should be focused on it. Especially considering the area occupied by swamps on the territory of the Russian Federation.

\section{References}

1. A. A. Zemtsova, 2nd edition, Sibnet 72 (2000)

2. V. L. Telitsyn, Technogenic evolution and optimal use of soils in swamp systems $\mathbf{2 6 1}$ (2004) 
3. N. M. Chumakov, Nature 5, 66-80 (1997)

4. V. A. Zubakov, Global climate events in the Pleistocene 286 (1986)

5. A. A. Sirin, A. A. Maslov, N. A. Valyaeva, O. P. Tsyganova, T. V. Glukhova, Forest Science 65-71 (2014)

6. A. A. Konoplyanik, Oil industry 4, 1-5 (2000)

7. G. I. Glagoleva, Modern Research and Development 3 (20), 706-709 (2018)

8. T. A. Rudich, O. A. Tkacheva,bApplication of geoinformation systems in ensuring the rational use of natural resources, International Student Scientific Bulletin 4-4, 534535 (2016)

9. O. V. Bogdanova, E. G. Chernykh, A. V. Kryakhtunov, Revista ESPACIOS 39 (16), 36 (2018) http://www.revistaespacios.com/a18v39n16/a18v39n16p36.pdf

10. V. A. Budarova, N. V. Cherezova, N. G. Martynova, Yu. D. Medvedeva, A. V. Dubrovsky, RevistaESPACIOS $39 \quad$ (16), $37 \quad$ (2018) http://www.revistaespacios.com/a18v39n16/18391637.html

11. V. A. Budarova, N. G. Martynova, Yu. D. Medvedeva, V. P. Budarov, $\begin{array}{llll}\text { RevistaESPACIOS } & 39 & \mathbf{( 2 6 ) ,} & 22\end{array}$ http://www.revistaespacios.com/a18v39n26/18392622.html

12. A. V. Budarova, N. G. Martynova, Yu. D. Medvedeva, V. P. Budrov, Oil and gas of Western Siberia: materials of the scientific and technical International Conference, 200-202 (2017)

13. A. V. Budarova, Yu. D. Medvedeva, N. G. Cherdantseva, Bulletin SSGA 2 (34), 169183 (2016)

14. A. P. Karpik, Methodological and technological bases of geoinformation support of territories (Novosibirsk: SGGA, 260, 2004)

15. V. A. Zheleznyakov, Development of a methodology for geoinformation operational updating of large-scale electronic maps using a spatial data bank 140 (2014)

16. M. I. Neustadt, L. K. Malik, Nature 11, 24-35 (1980)

17. V. V. Malakhov, E. N. Golubeva, A. V. Eliseev, G. A. Platov, International Conference on Environmental Observations, Modelling and Information Systems: Enviromis-2018, Session 2, 94-98 (2018)

18. V. L. Telitsyn, Yu. A. Novikov, Oil and gas 4, 130-136 (2018) 